\title{
Effects of Family Health of Elderly People in Rural Areas on Their Preparation for Old Age -Focused on the mediating effect of self-efficacy-
}

\section{농촌지역 노인의 가족건강성이 노후준비에 미치는 영향 -자기효능감의 매개효과를 중심으로-}

Yun-Seong $\mathrm{Um}^{1}$, Jea-Ug Ko ${ }^{2}$

엄윤성 ${ }^{1}$, 고재욱 2

${ }^{1}$ Doctor, Department of Social Welfare, Catholic Kwandong University, Korea,yw5955@daum.net.

${ }^{2}$ Professor, Department of Social Welfare, Catholic Kwandong University, Korea,kojea62@ cku.ac.kr

Corresponding author: Jea-Ug Ko

\begin{abstract}
This study examines the family health of elderly people in rural areas, their preparation for old age, and their self-efficacy. Furthermore, it aims to suggests measures for the elderly's preparation for old age in rural areas of an aging society. The subjects were 550 elderly men and women aged 60 and over living in rural areas in Gangwon-do. The measurement tool of this study consisted of physical, economic, emotional, and leisure activities as sub-factors of preparation for old age. Family health was defined as family resilience, mutual respect, strong bonds, economic stability, and family culture. Also, self-efficacy was composed of social efficacy, self-acceptance, and self-fulfillment. The main findings of this study are as follows. First, family health was found to influence self-efficacy. Second, selfefficacy has an effect on preparation for old age. Third, family health has an effect on preparation for old age. Fourth, self-efficacy showed an indirect mediating effect when family health had an effect on preparation for old age. As such, the family health and self-efficacy of the elderly in rural areas are important factors influencing their preparation for old age.According to the results of this study, it was found that it acts as an important factor for improving family health, self-efficacy, and preparation for old age of the elderly in rural areas. It also suggests the need for economically helpful job creation in the process of developing an education program for senior citizens to enhance self-efficacy among the elderly in rural areas and increasing their preparation for old age. Therefore, the results of this study is intended to help in preparing elderly welfare programs and services in rural areas as a policy and action plan to enhance self-efficacy to increase family members' preparation for old age.
\end{abstract}

Keywords: Elderly People in Rural Areas, Family Health, Self-efficacy, and Preparation for Old Age

요약: 본 연구는 농촌지역 노인의 가족건강성과 노후준비, 자기효능감에 관한 연구이다. 고령사회 농촌지역 노인들의 노후준비 방안에 그 목적을 두고자 한다. 본 연구의 조사대상은 강원도 남.여 60 세 이상 농촌 지역에 거주하는 노인 550명을 대상으로 실시하였다. 연구의 본 연구의 측정도구는 노후준비 하위요인으로 신체적, 경제적, 정서적, 여가 활동으로 구성하였다. 가족건강성은 가족 탄력, 상호존중, 유대강화, 경제 안정, 가족 문화로 하였다.

Received: September 15, 2021; $1^{\text {st }}$ Review Result: October 30, 2021; $2^{\text {nd }}$ Review Result: December 18, 2021 Accepted: January 29, 2022 
또한 자기 효능감 측정은 사회적 효능, 자기 수용, 자기 성취로 구성하였다. 본 연구의 주요 결과는 다음과 같다. 첫째, 가족건강성은 자기효능감에 영향을 미치는 것으로 나타났다. 둘째, 자기효능감은 노후준비에 영향을 미치는 것으로 나타났다. 셋째, 가족건강성은 노후준비에 영향을 미치는 것으로 나타났다. 넷째, 가족건강성이 노후준비에 미치는 영향에 대한 자기효능감은 간접매개효과를 보였다. 이와 같은 연구 결과에 따라 농촌지역 노인의 가족건강성 향상과 자기효능감 증진 및 노후준비 증대를 위한 중요한 요인으로 작용하는 것으로 나타났다, 이에 농촌노인복지서비스는 농촌 노인에게 적절한 프로그램과 정책이 노인 도시 노인과 차별화되는 농촌노인복지정책이 필요하다. 또한 농촌지역 노인의 자기효능감 증진을 위한 경로당 교육프로그램 개발과 노후준비를 증대시키는 과정에서 경제적으로 도움이 되는 일자리 창출 확대의 필요성을 제시한다. 따라서 가족 구성원의 노후준비 증대를 위한 자기효능감 증진 강화정책과 실천방안으로 농촌지역 노인의 노인복지 프로그램 및 서비스 마련에 도움이 되기를 기대한다.

핵심어: 농촌 지역 노인, 가족 건강성, 자기효능감, 노후준비

\section{1. 서론}

\section{1 연구의 필요성}

최근 가장 중요하게 이슈화되고 있는 가족 특성은 가족건강성이라 할 수 있다. 이는 가족건강성이 노후준비에 지대한 영향을 미친다는 연구 결과들이 증가하기 때문에 알 수 있다. 가족건강성은 노후준비의 증대를 위한 가장 기본적인 환경적 요인으로 그 중요성을 인식하게 되었다. 따라서 농촌지역 노인의 가족건강성이 자기효능감의 매개 역할을 함으로써 노후준비에 미치는 영향을 살펴보고자 한다. 오늘날의 농촌지역은 도시화, 산업화로 인해 가족환경이 변화되어 노인분들만 거주하며 노후까지 농사일에 자신의 삶을 다한다[1]. 이에 가족건강성에 대한 연구는 다차원적으로 이루어져야 한다[2]. 이처럼 농촌지역 노인의 노후준비에 대한 욕구를 충족시키기 위해 자기효능감을 통하여 노인의 역할과 기능을 회복시킬 수 있는 가족건강성이 지속해서 유지되어야 할 것이다. 인간의 행동 변화는 적극적이고 창조적인 삶을 설명하고 예언하기 위한 인지적 관점의 하나로 자기효능감을 설정하였고, 행동의 변화를 설명하고 예언하기 위해서인지 행동적인 관점의 하나로 자기효능감이란 개념을 도입하였다[3]. 농촌지역에는 자신의 논과 밭이나 마을 사람들과 지속적인 상호작용을 통해 자기효능감을 증진할 수 있다[4]. 이처럼 가족건강성 향상으로 이어질 수 있음으로 노후준비를 증대시킬 수 있는 좋은 환경이라 할 수 있다. 노인 인구가 증가했던 선진국의 노인들은 개인적으로 노후준비를 하였으며, 국가적으로도 노후준비를 실행하여 비교적 안정된 노후를 보내고 있다. 반면 급변한 우리 사회 근대화를 겪는 우리 사회는 개인뿐만 아니라 국가정책으로도 노후준비가 매우 미약하며, 특히 준비되지 않은 경제적 노후준비의 심각성은 종종 이슈화되고 있다[5]. 이에 선진국에서는 노동력 부족, 사회보험제도의 개혁, 과도한 복지비용 지출로 인한 재정부담 등을 경험하고 있다. 이들 국가가 격는 고령화 문제는 고령화 속도가 훨씬 빠른 한국 사회에 시사점이 크다[6]. 본 연구에서는 향후 농촌지역 노인들은 노후에 필요한 자원들을 마련하고 농촌지역 특성에 맞는 노후생활을 대비하여 환경 개선은 물론 삶의 질 향상을 위한 대안이 매우 중요한 매체 활용으로 등장한 것은 
사실이다. 노인의 주제 연구는 도시노인들에 대한 연구가 대부분이다.

\section{2 연구 문제}

본 연구는 농촌지역 노인의 가족건강성과 노후준비, 자기효능감 관계를 연구하여 고령화 시대 노후준비 증대에 그 목적을 두고자 한다. 이에 본연구는 가족건강성이 노후준비에 미치는 영향에 대해서 자기효능감은 매개 효과 영향 관계를 연구하고자 한다.

\section{2. 이론적 배경과 선행 연구 검토}

농촌지역 노인들은 농촌에서 발생하는 여러 환경적 특성들이 추가되어 일반적인 노인과 구 분된다[7]. 특히 농촌지역 노인들은 직업병이라고 하는 손발 저림, 두통 증상을 수반하는 농부 증이 나타난다[8]. 더욱이 농촌지역 노인들이 농사일을 천직으로 하고 살아왔기 때문에 노후준 비가 적절히 이루어지지 못했으며 더 많은 질병에 노출된다.

농촌지역 노인의 환경과 직업병은 자기효능감 및 노후준비에 상관관계가 있다. 자기효능감과 노후준비의 관계는 연구들이 많지 않지만, 행동으로 옮기려는 변화는 상당한 증거가 있다[9]. 예를 들어 금연한다. 건강검진을 받는다. 체력단련을 한다는 것은 자기효능감을 증진하기 위한 행동의 변화로서 긍정적인 건강 결과를 획득하려는 행위로 노후준비 행동의 신체적 측면에 해당한다[10]. 자기효능감과 가족건강성의 관계는 가족원 간의 유대, 가족원 간의 의사소통, 가족원 간의 가치체계 공유, 가족원 간의 문제해결 능력 등의 특성을 포함하고 있어 자기효능감과 매우 밀접한 관계를 맺고 있다[11]. 특히 가족건강성은 생활환경이 자기효능감을 증진하는 중요한 요소로 자신이 처한 상황을 효과적으로 처리하기 위한 행동 과정을 잘 수행할 수 있는 것에 관한 판단으로부터 얻어진다고 하였다[12]. 아동에서 대학생, 중년 그리고 노인에 이르기까지 다수의 연구를 통해 가족건강성에 대한 연구가 이루어졌는데[13], 가족건강성을 높게 인식한다[14]. 가족건강성과 노후준비의 관계는 가족건강성이 높은 가족이 사회변화 및 생애주기별 환경에 효과적으로 대처하는 건강한 가족이다[15]. 더불어 노후준비는 일반적으로 신체, 경제 측면의 범주에서 이루어지고 있음을 알 수 있다[16]. 가족건강성, 자기효능감, 노후준비 관계에 관한 선행 연구에서는 농촌지역 노인의 가족건강성이 노후준비에 영향을 주고 있는 것으로 나타났다. 따라서 농촌지역 노인이 자기효능감이 가족건강성의 개념이 상대적으로 영향 관계가 있었으며 다양하게 정의되는 만큼 노후준비를 연구하는 데 있어, 많은 시사점을 얻을 수 있을 것이다[17]. 이를 근거로 하여 본 연구는 농촌지역노인의 가족건강성과 노후준비, 자기통제력 관계를 연구하여 노후준비 대안 기초 자료를 제공하고자 한다. 본 연구는 노후준비 하위 요인으로 신체노후, 경제노후, 정서노후, 여가노후, 그리고 가족건강성 하위요인으로는 가족탄력, 상호존중, 질적유대, 경제안정, 가족문화로 구성하였다. 자기효능감의 하위요인으로 사회효능, 자기수용, 자기성취로 구성하여 연구하였다.

\section{3. 연구방법}

본 연구는 농촌지역 노인의 가족건강성이 노후준비에 미치는 자기효능감 관계를 살펴보고자 한다. 이에 연구 가설로 농촌지역 노인의 자기효능감은 가족건강성과 
노후준비 간에 매개효과를 검증하고자 한다.

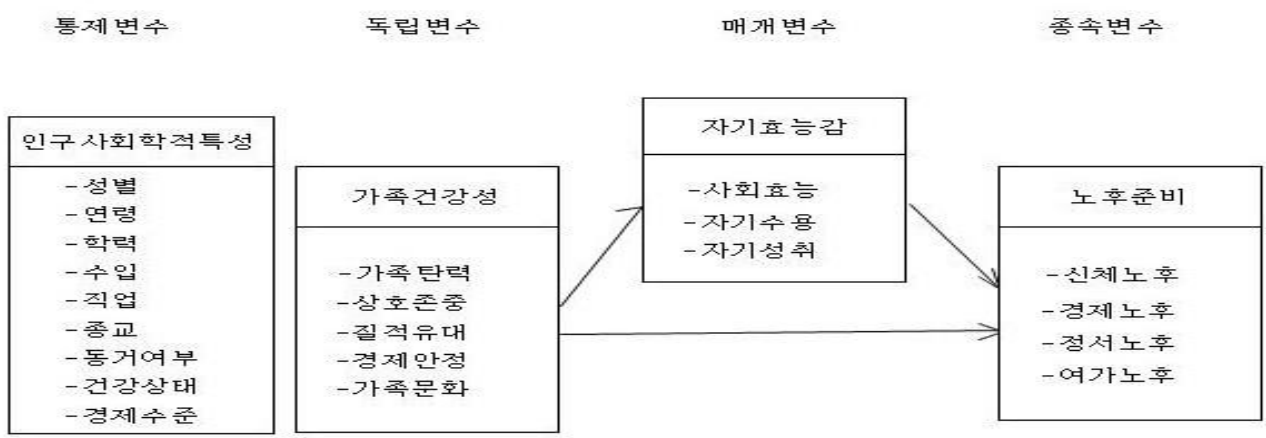

[그림 1] 연구모형

[Fig.1] Research Models

\section{1 연구대상}

조사대상은 $\mathrm{G}$ 도 남.여 60 세 이상 농촌 지역에 거주하는 노인 550명을 대상으로 실시하였다. 전형적인 농촌지역에 거주하는 60 세 이상 노인으로 $\mathrm{Y}$ 군, $\mathrm{P}$ 군, $\mathrm{J}$ 군에 거주하고 있는 관내 경로당과 전통시장, 보건소와 노인복지센터 사회복지관 그리고 사회복지협의회 방문 또는 내방자의 노인 중에서 본 조사의 취지에 협조한 노인이다. 이 중 불성실한 9부를 제외하고 541부를 분석에 사용하였다. 조사는 2018년 4월에 예비조사를 하였으며, 본 조사는 5 월부터 6 월까지 약 2 개월간 두 차례에 걸쳐 실시하였다.

\section{2 연구도구}

\subsection{1 종속변수: 노후준비}

본 연구에 사용되는 종속변수의 노후 준비성에 관한 척도이다[18]. 그리고 많은 연구에서 설문 내용을 참고하여 사용되었다[19]. 본 연구에서는 농촌지역 노인의 특성에 맞게 총 15 문항으로 수정, 보완하였다. 응답범주는 자기 기입방법의 Likert척도이며 각 문항에 대한 하위 요인으로 신체노후 4개 문항, 경제노후 4문항, 정서노후 4개 문항, 여가노후 3개 문항으로 5점으로 답하도록 구성되었다.

\subsection{2 독립변수: 가족건강성}

본 연구에 사용된 독립변수로 가족건강성 척도는 농촌지역 노인의 가족건강성을 측정하기 위해 한국형 가족건강성 척도 II(KFSS-II)를 사용하였다[20]. 이 척도는 기존의 가족건강성 척도 사용 중에 제기된 문제를 수정 보완하여 문항 수를 줄이고 문장을 좀 평이하게 수정 구성하여 여러 연령층과 다양한 사람들을 대상으로 연구의 도구로 사용할 수 있게 개발된 척도이다[21]. 본 연구에서 척도 문항을 농촌지역 노인들의 특성에 맞게 수정 보완하여 사용하였다. 가족건강성에 사용된 척도는 가족탄력 4 문항, 상호존중 4 문항, 질적유대 3 문항, 경제안정 3 문항, 가족문화 2 문항으로 5 개 하위 요인 총 16문항으로 5점 Likert 척도로 하였다. 


\subsection{3 매개변수: 자기효능감}

본 연구에 사용된 매개변수로 자기효능감 척도를 기반으로 하였다[12]. 이를 수정 보완하여 자기효능감 척도를 사용하였다[22]. 본 연구에서는 9문항으로 농촌지역 노인들의 특성에 맞게 보완 사용하였다. 자기효능감의 척도에 사용된 문항은 총 3 개 요인으로 사회효능 3문항, 자기수용 3문항, 자기성취 3문항으로 응답범주는 Likert식 5점 척도로 하였다.

\subsection{4 통제변수: 인구사회학적 특성}

인구사회학적 특성에 관해서는 변인인 성별, 연령, 학력, 월수입, 직업, 종교, 동거가족, 건강상태 및 경제적으로 구분하여 총 9문항으로 하였다.

\section{3 측정변수의 신뢰도}

[표 1]측정변수에 대한 신뢰도 검증

[Table 1] Reliability Verification of Measurement Variables

\begin{tabular}{l|l|l|l}
\hline \multicolumn{2}{c}{ 구분 } & \multicolumn{2}{|c}{ Cronbach's $\alpha$} \\
\hline & 가족탄력 & .935 & \\
가족건강성 & 상호존중 & .959 & .937 \\
& 질적유대 & .923 & .928 \\
& 경제안정 & .710 & \\
\hline & 가족문화 & .893 \\
노후준비 & 신체노후 & .859 & \\
& 경제노후 & .849 & .871 \\
& 정서노후 & .890 & .832 \\
\hline
\end{tabular}

\section{4 자료처리 및 분석방법}

본 연구에서는 설문지의 데이터 코딩을 거쳐 SPSS ver 19.0 을 사용하여 통계적 자료처리를 하였으며, 유의수준은 $\mathrm{p}<0.05$ 로 설정하여 분석하였다. 첫째, 표본의 인구통계학적 특성을 분석하기 위하여 빈도수와 백분율을 산출하는 빈도분석을 하였다. 둘째, 측정변수에 대한 타당성 검증을 위하여 요인분석을 하였다. 셋째, 측정변수에 대한 신뢰도 검증을 위하여 내적 일관성을 분석할 수 있는 Cronbach's $\alpha$ 값을 사용하였다. 넷째, 측정변수의 분포를 분석하기 위하여 기술통계분석을 하였다. 다섯째, 측정변수 간의 상관관계를 분석하기 위하여 상관분석을 하였다. 여섯째, 가족건강성, 자기효능감, 노후준비의 인과관계를 분석하기 위하여 다중회귀분석을 실시하였다. 일곱째, 가족건강성이 노후준비에 미치는 영향에 대한 자기효능감의 매개효과를 분석하기 위하여 3 단계 매개효과 분석을 시행하였으며 유의성 검증을 위하여 sobel test 를 실시하였다. 


\section{4. 연구결과}

\section{1 표본의 인구사회학적 특성에 대한 분석}

연구대상의 인구사회학적 특성에 대해서 분석을 실시한 결과, 성별 분포는 남성이 178 명(32.9\%), 여성은 363 명 $(67.1 \%)$ 으로 남성보다 185 명(34.2\%) 많았다. 이는 현재 농촌 노인의 성비 구성에서 여성이 더 많다는 사실과 부합되는 비율이다. 연령별 분포 분석결과 75-79세가 226명(41.8\%)으로 가장 많았으며, 70-74세가 129명(23.8\%), 65-69세가 127 명(23.5\%), 80세 이상이 30명(5.5\%)이며 그리고 60-64세가 29명(5.4\%) 순으로 나타났다.

학력에서는 초등학교 졸업이 285명(52.7\%)으로 가장 많았으며, 중학교 졸업이 109 명(20.1\%), 고등학교 졸업이 98명(18.1\%), 그리고 대학교 졸업 이상이 49명(9.1\%)으로 농촌지역 노인의 교육수준이 높지 않은 결과로 이해 된다. 월수입에서는 100 만원 미만이 246 명(45.5\%)으로 가장 많았으며, 100 만원 이상-300만원 미만이 234명(43.3\%),300만원 이상 61 명(11.3\%) 순으로 100 만원 미만이 가장 많은 비율을 차지하였다.

직업에서는 없다가 283 명(52.3\%), 있다가 258 명(47.7\%)이며, 종교에서는 있다가 346 명 $(64.0 \%)$, 없다가 195 명 $(36.0 \%)$ 이었다. 동거 여부에서는 동거가 361 명 $(64.0 \%)$, 비동거가 180 명 $(33.3 \%)$ 으로 나타났다. 이는 농촌지역의 단독세대가 증가하는 추세로 볼 수 있다. 건강상태에서는 보통이 241 명(44.5\%)으로 가장 많았으며, 좋음 183 명 $(33.8 \%)$, 그리고 나쁨이 117 명 $(21.6 \%)$ 순이었다. 경제력에서는 보통이 283 명 $(52.3 \%)$ 으로 가장 많았으며, 좋음이 169명(31.2\%), 그리고 나쁨 89명(16.5\%)의 순을 보였다.

[표 2] 인구사회학적 특성에 대한 분석

[Table 2] Analysis of Demographic Characteristics

\begin{tabular}{|c|c|c|c|}
\hline \multicolumn{2}{|r|}{ 구 분 } & 빈도 & 퍼센트 \\
\hline \multirow{2}{*}{ 성별 } & 남성 & 178 & 32.9 \\
\hline & 여성 & 363 & 67.1 \\
\hline \multirow{5}{*}{ 연령 } & 60-64세 & 29 & 5.4 \\
\hline & 65-69세 & 127 & 23.5 \\
\hline & 70-74세 & 129 & 23.8 \\
\hline & 75-79세 & 226 & 41.8 \\
\hline & 80세 이상 & 30 & 5.5 \\
\hline \multirow{4}{*}{ 학력 } & 초졸 & 285 & 52.7 \\
\hline & 중졸 & 109 & 20.1 \\
\hline & 고졸 & 98 & 18.1 \\
\hline & 대졸 이상 & 49 & 9.1 \\
\hline \multirow{2}{*}{ 월수입 } & 100 만원 미만 & 246 & 45.5 \\
\hline & 100 만원 이상-300만원 미만 & 234 & 43.3 \\
\hline
\end{tabular}




\begin{tabular}{|c|c|c|c|}
\hline & 300 만원 이상 & 61 & 11.3 \\
\hline \multirow{2}{*}{ 직업 } & 있다 & 258 & 47.7 \\
\hline & 없다 & 283 & 52.3 \\
\hline \multirow{2}{*}{ 종교 } & 있다 & 346 & 64.0 \\
\hline & 없다 & 195 & 36.0 \\
\hline \multirow{2}{*}{ 동거가족 } & 동거 & 361 & 66.7 \\
\hline & 비동거 & 180 & 33.3 \\
\hline \multirow{3}{*}{ 건강상태 } & 나쁨 & 117 & 21.6 \\
\hline & 보통 & 241 & 44.5 \\
\hline & 좋음 & 183 & 33.8 \\
\hline \multirow{3}{*}{ 경제력 } & 나쁨 & 89 & 16.5 \\
\hline & 보통 & 283 & 52.3 \\
\hline & 좋음 & 169 & 31.2 \\
\hline \multicolumn{2}{|c|}{ 합계 } & 541 & 100.0 \\
\hline
\end{tabular}

\section{2 측정변수에 대한 상관관계 분석}

[표 3] 측정변수대한상관관계분석

[Table 3] Correlation Analysis for Measurement Variables

\begin{tabular}{|c|c|c|c|c|c|c|c|c|c|c|c|c|}
\hline $\begin{array}{l}\text { 구 분 } \\
\text { 가족 } \\
\text { 탄력 }\end{array}$ & $\begin{array}{c}\text { 가족 } \\
\text { 탄력 } \\
1 \\
1\end{array}$ & $\begin{array}{l}\text { 상호 } \\
\text { 존중 }\end{array}$ & $\begin{array}{l}\text { 질적 } \\
\text { 유대 }\end{array}$ & $\begin{array}{l}\text { 경제 } \\
\text { 안정 }\end{array}$ & $\begin{array}{l}\text { 가족 } \\
\text { 문화 }\end{array}$ & $\begin{array}{l}\text { 신체 } \\
\text { 노후 }\end{array}$ & $\begin{array}{l}\text { 경제 } \\
\text { 노후 }\end{array}$ & $\begin{array}{l}\text { 정서 } \\
\text { 노후 }\end{array}$ & $\begin{array}{l}\text { 여가 } \\
\text { 노후 }\end{array}$ & $\begin{array}{l}\text { 사회 } \\
\text { 효능 }\end{array}$ & $\begin{array}{l}\text { 자기 } \\
\text { 수용 }\end{array}$ & $\begin{array}{l}\text { 자기 } \\
\text { 성취 }\end{array}$ \\
\hline $\begin{array}{l}\text { 상호 } \\
\text { 존중 }\end{array}$ & $\begin{array}{c}.826^{* *} \\
*\end{array}$ & 1 & & & & & & & & & & \\
\hline $\begin{array}{l}\text { 질적 } \\
\text { 유대 }\end{array}$ & $\begin{array}{c}688^{* *} \\
*\end{array}$ & $\begin{array}{c}.711^{* *} \\
*\end{array}$ & 1 & & & & & & & & & \\
\hline $\begin{array}{l}\text { 경제 } \\
\text { 안정 }\end{array}$ & $\begin{array}{c}.568^{* *} \\
*\end{array}$ & $\begin{array}{c}.587^{* *} \\
*\end{array}$ & $\begin{array}{c}.772^{* *} \\
*\end{array}$ & 1 & & & & & & & & \\
\hline $\begin{array}{l}\text { 가족 } \\
\text { 문화 }\end{array}$ & $\begin{array}{c}.446^{* *} \\
*\end{array}$ & $\begin{array}{c}.439^{* *} \\
*\end{array}$ & $\begin{array}{c}.439^{* *} \\
*\end{array}$ & $\begin{array}{c}.488^{* *} \\
*\end{array}$ & 1 & & & & & & & \\
\hline $\begin{array}{l}\text { 신체 } \\
\text { 노후 }\end{array}$ & $\begin{array}{c}443^{* *} \\
*\end{array}$ & $\begin{array}{c}.421^{* *} \\
*\end{array}$ & $\begin{array}{c}497^{* *} \\
*\end{array}$ & $\begin{array}{c}.450^{* *} \\
*\end{array}$ & $\begin{array}{c}.364^{* *} \\
*\end{array}$ & 1 & & & & & & \\
\hline $\begin{array}{l}\text { 경제 } \\
\text { 노후 }\end{array}$ & $\begin{array}{c}410^{* *} \\
*\end{array}$ & $\begin{array}{c}370^{* *} \\
*\end{array}$ & $\begin{array}{c}.362^{* *} \\
*\end{array}$ & $\begin{array}{c}.423^{* *} \\
*\end{array}$ & $\begin{array}{c}.516^{* *} \\
*\end{array}$ & $\begin{array}{c}.540^{* *} \\
*\end{array}$ & 1 & & & & & \\
\hline $\begin{array}{l}\text { 정서 } \\
\text { 노후 }\end{array}$ & $\begin{array}{c}.620^{* *} \\
*\end{array}$ & $\begin{array}{c}.694 * * \\
*\end{array}$ & $\begin{array}{c}.630^{* *} \\
*\end{array}$ & $\begin{array}{c}.587 * * \\
*\end{array}$ & $\begin{array}{c}.398^{* *} \\
*\end{array}$ & $\begin{array}{c}.501 * * \\
*\end{array}$ & $\begin{array}{c}.524 * * \\
*\end{array}$ & 1 & & & & \\
\hline $\begin{array}{l}\text { 여가 } \\
\text { 노후 }\end{array}$ & $\begin{array}{c}458^{* *} \\
*\end{array}$ & $\begin{array}{c}.466^{* *} \\
*\end{array}$ & $\begin{array}{c}.579^{* *} \\
*\end{array}$ & $\begin{array}{c}610^{* *} \\
*\end{array}$ & $\begin{array}{c}.353^{* *} \\
*\end{array}$ & $\begin{array}{c}.566^{* *} \\
*\end{array}$ & $\begin{array}{c}.510^{* *} \\
*\end{array}$ & $\begin{array}{c}.649 * * \\
*\end{array}$ & 1 & & & \\
\hline
\end{tabular}


Effects of Family Health of Elderly People in Rural Areas on Their Preparation for Old Age -Focused on the mediating effect of self-efficacy-

\begin{tabular}{|c|c|c|c|c|c|c|c|c|c|c|c|c|}
\hline $\begin{array}{l}\text { 사회 } \\
\text { 효능 }\end{array}$ & $\begin{array}{c}.555^{* *} \\
*\end{array}$ & $\begin{array}{c}.604^{* *} \\
*\end{array}$ & $\begin{array}{c}.533^{* *} \\
*\end{array}$ & $\begin{array}{c}.451^{* *} \\
*\end{array}$ & $\begin{array}{c}.395^{* *} \\
*\end{array}$ & $\begin{array}{c}.489^{* *} \\
*\end{array}$ & $\begin{array}{c}.402 * * \\
*\end{array}$ & $\begin{array}{c}.657^{* *} \\
*\end{array}$ & $\begin{array}{c}.444^{* *} \\
*\end{array}$ & 1 & & \\
\hline $\begin{array}{l}\text { 자기 } \\
\text { 수용 }\end{array}$ & $\begin{array}{c}.405^{* *} \\
*\end{array}$ & $\begin{array}{c}.418^{* *} \\
*\end{array}$ & $\begin{array}{c}.461 * * \\
*\end{array}$ & $\begin{array}{c}.431 * * \\
*\end{array}$ & $\begin{array}{c}.219^{* *} \\
*\end{array}$ & $\begin{array}{c}.450^{* *} \\
*\end{array}$ & $\begin{array}{c}.291 * * \\
*\end{array}$ & $\begin{array}{c}.438^{* *} \\
*\end{array}$ & $\begin{array}{c}.381 * * \\
*\end{array}$ & $\begin{array}{c}.526^{* *} \\
*\end{array}$ & 1 & \\
\hline $\begin{array}{l}\text { 자기 } \\
\text { 성취 }\end{array}$ & $\begin{array}{c}.456^{* *} \\
*\end{array}$ & $\begin{array}{c}.470^{* *} \\
*\end{array}$ & $\begin{array}{c}.563^{* *} \\
*\end{array}$ & $\begin{array}{c}.627^{* *} \\
*\end{array}$ & $\begin{array}{c}.430^{* *} \\
*\end{array}$ & $\begin{array}{c}.545^{* *} \\
*\end{array}$ & $\begin{array}{c}.586^{* *} \\
*\end{array}$ & $\begin{array}{c}.611^{* *} \\
*\end{array}$ & $\begin{array}{c}.663^{* *} \\
*\end{array}$ & $\begin{array}{c}.512^{* *} \\
*\end{array}$ & $\begin{array}{c}.419^{* *} \\
*\end{array}$ & 1 \\
\hline
\end{tabular}

$* * * \mathrm{p}<.001$

측정 변수에 대한 상관 관계를 분석한 결과, 가족 건강성, 노후 준비, 자기 효능감의 하위 변수간에는 모두 유의하게정(+)의 상관관계를 보이는 것으로 나타났다. 상관관계 숫값이 0.219-0.826 으로 상관관계가 모두 유의수준 $0.1 \%$ 수준에서 유의한 것으로 나타나고있었다. 즉 이러한 상관 분석 결과는 본 연구자가 설정한 연구방향과 동일한 것으로 나타나고 있어 판별 타당성이 확보되었다고 볼 수 있을 것이다.

\section{3 측정변수에 대한 기술통계 분석}

[표 4] 측정변수에대한기술통계분석

[Table 4] Descriptive Statistical Analysis of Measurement Variables

\begin{tabular}{|c|c|c|c|c|c|c|}
\hline \multicolumn{2}{|c|}{ 구 분 } & $\mathrm{N}$ & 평균 & 표준편차 & 왜도 & 첨도 \\
\hline \multirow{6}{*}{$\begin{array}{c}\text { 가족 } \\
\text { 건강성 }\end{array}$} & 가족탄력 & 541 & 3.49 & .88 & -.44 & .24 \\
\hline & 상호존중 & 541 & 3.47 & .91 & -.45 & .06 \\
\hline & 질적유대 & 541 & 2.72 & .98 & .12 & -.41 \\
\hline & 경제안정 & 541 & 2.65 & .99 & .12 & -.43 \\
\hline & 가족문화 & 541 & 3.01 & .95 & .09 & -.32 \\
\hline & 전체 & 541 & 3.12 & .79 & -.11 & -.11 \\
\hline \multirow{5}{*}{ 노후준비 } & 신체노후 & 541 & 3.16 & .75 & -.13 & .24 \\
\hline & 경제노후 & 541 & 2.77 & .95 & .33 & -.34 \\
\hline & 정서노후 & 541 & 3.26 & .88 & -.17 & -.28 \\
\hline & 여가노후 & 541 & 2.62 & .97 & .17 & -.59 \\
\hline & 전체 & 541 & 2.98 & .72 & .16 & -.17 \\
\hline \multirow{4}{*}{$\begin{array}{c}\text { 자기 } \\
\text { 효능감 }\end{array}$} & 사회효능 & 541 & 3.69 & .85 & -.22 & -.31 \\
\hline & 자기수용 & 541 & 3.45 & .94 & -.75 & .25 \\
\hline & 자기성취 & 541 & 2.92 & .92 & .05 & -.37 \\
\hline & 전체 & 541 & 3.35 & .73 & -.44 & .24 \\
\hline
\end{tabular}

측정변수에 대한 기술통계분석을 실시한 결과, 가족건강성에서는 3.12 로 보통 정도의 수준을 보였다. 하위변수를 보면, 가족탄력, 상호존중, 가족문화는 평균이 3.0 이상으로 보통 이상이며, 질적유대, 경제안정에서는 평균이 3.0 이하로서 보통 이하를 보였다. 노후준비에서는 2.98 로 보통 수준을 보였다. 하위변수를보면, 정서노후, 신체노후는 평균이 3.0 이상으로 보통 이상이며, 경제노후, 여가노후에서는 평균이 3.0 이하로서 보통 이하 였다. 자기효능감에서는 3.35 로 다소높게 나타났다. 하위변수를 보면, 사회효능, 
자기수용은 높지만. 자기성취는 2.92 로 다소 낮았다. 그리고 모든 변수의 왜도와 첨도 값이 모두-1.96 부터 1.96 사이에 존재하고 있어 정규성이 확보되었다고 볼 수 있다.

\section{5. 연구가설 검증 결과}

농촌지역 노인의 가족건강성과 노후준비 간에 자기효능감은 매개효과를 보일 것이다 란 검증 결과는 다음과 같다.

농촌지역 노인의 가족건강성과 노후준비 간에 자기효능감의 매개효과를 분석하기 위하여 3 단계 매개효과를 분석하였다[23]. 매개효과가 존재하기 위해서는 다음과 같은 3 개 단계를 충족되어야 한다. 첫째, 1 단계에서 독립변수가 매개변수에 유의미한 영향을 미쳐야 한다. 둘째, 2 단계에서 독립변수는 종속변수에 유의미한 영향을 미쳐야 한다. 셋째, 3 단계에서 독립변수와 매개변수를 모두 투입하여 분석하였을 때 매개변수는 종속변수에 영향을 미쳐야 하며, 독립변수의 영향력은 2 단계보다 감소하거나 없어야 한다. 이때 독립변수의 영향력이 감소하면 간접매개효과를 보인다고 하며, 영향력이 없다면 직접매개효과를 보인다고 할 수 있다.

[표 5] 가족건강성이노후준비에미치는영향에대한자기효능감의매개효과분석

[Table 5] Analysis of the Mediating Effect of Self-efficacy in Family Health Influencing Old Age

\begin{tabular}{|c|c|c|c|c|c|c|c|c|}
\hline \multirow{2}{*}{ 종속변수 } & \multirow{2}{*}{ 독립변수 } & \multicolumn{2}{|c|}{ 비표준화 계수 } & \multirow{2}{*}{$\begin{array}{c}\text { 표준화 } \\
\text { 계수 }\end{array}$} & \multirow{2}{*}{$\mathrm{R}^{2}$} & \multirow{2}{*}{$\mathrm{F}$} & \multirow{2}{*}{$\mathrm{t}$} & \multirow{2}{*}{$\mathrm{p}$} \\
\hline & & B & 표준오차 & & & & & \\
\hline \multirow{2}{*}{$\begin{array}{c}\text { 자기 } \\
\text { 효능감 }\end{array}$} & (상수) & 1.336 & .093 & & \multirow[b]{2}{*}{.483} & \multirow[b]{2}{*}{$503.441^{* * *}$} & 14.410 & .000 \\
\hline & $\begin{array}{c}\text { 가족 } \\
\text { 건강성 }\end{array}$ & .647 & .029 & .695 & & & $22.437 * * *$ & .000 \\
\hline \multirow{2}{*}{$\begin{array}{l}\text { 노후 } \\
\text { 준비 }\end{array}$} & (상수) & .951 & .089 & & \multirow[b]{2}{*}{.505} & \multirow[b]{2}{*}{$549.724 * * *$} & 10.672 & .000 \\
\hline & $\begin{array}{c}\text { 가족 } \\
\text { 건강성 }\end{array}$ & .649 & .028 & .711 & & & $23.446^{* * *}$ & .000 \\
\hline \multirow{3}{*}{$\begin{array}{l}\text { 노후 } \\
\text { 준비 }\end{array}$} & (상수) & .298 & .090 & & \multirow{3}{*}{.633} & \multirow{3}{*}{$463.610^{* * *}$} & 3.299 & .001 \\
\hline & $\begin{array}{c}\text { 가족 } \\
\text { 건강성 }\end{array}$ & .333 & .033 & .365 & & & $10.045^{* * *}$ & .000 \\
\hline & $\begin{array}{c}\text { 자기 } \\
\text { 효능감 }\end{array}$ & .488 & .036 & .497 & & & $13.689 * * *$ & .000 \\
\hline
\end{tabular}

Sobel test : $\mathrm{z}=11.585^{* * * *}$

$* * * \mathrm{p}<.001$

가족건강성이 노후준비에 미치는 영향에 대한 자기효능감의 매개효과를 분석하기 위하여 3 단계 매개효과를 분석한 결과, 1 단계에서는 독립변수인 가족건강성이 매개변수인 자기효능감에 정 $(+)$ 의 영향을 미치는 것으로 나타났다 $(\mathrm{t}=22.437, \mathrm{p}<0.001) . \quad 2$ 단계에서는 독립변수인 가족건강성이 종속변수인 노후준비에 정 $(+)$ 의 영향을 미치는 것으로 나타났다 $(\mathrm{t}=23.446, \mathrm{p}<0.001)$. 3 단계에서는 매개변수인 자기효능감이 노후준비에 정 $(+)$ 의 영향을 미치는 것으로 나타났으며, 독립변수인 가족건강성이 노후준비에 정 $(+)$ 의 영향을 미치는 것으로 나타났다. 그리고 독립변수의 3 단계 영향력이 2 단계보다 감소한 것으로 나타났다(0.711 -> 0.365). 또한 sobel test 결과 $\mathrm{z}=11.585$ 로서 통계적으로 유의미한 것으로 
나타나고 있었다. 따라서 가족건강성이 노후준비에 미치는 영향에 대해서 자기효능감은 간접매개효과를 보이는 것으로 나타나 가설은 채택되었다.

\section{6. 결론}

농촌지역 노인의 가족건강성이 자기효능감에 매개하여 노후준비에 미치는 영향을 알아본 결과 본 연구에서 설정한 방향성과 동일한 것으로 판별되어 연구의 타당성이 있다고 볼 수 있음으로, 연구를 통해 얻은 결과를 제시하면 다음과 같다.

첫째, 농촌지역 노인의 가족건강성과 자기효능감은 유의미한 관계가 있다. 더욱이 가족건강성이 향상될 때 자기효능감도 증진된다. 둘째, 자기효능감과 노후준비는 유의한 관계가 있다. 특히 자기효능감이 증진될수록 노후준비가 증대된다. 셋째, 농촌지역 노인의 가족건강성과 노후준비는 유의한 관계가 있다. 이는 가족건강성이 향상될 때 노후준비도 증대된다. 넷째, 농촌지역 노인의 가족건강성과 자기효능감은 노후준비에 유의한 영향을 미친다. 따라서 농촌지역 노인의 가족건강성과 자기효능감은 노후준비에 영향을 미치는 중요한 요인임을 의미한다.

본 연구 결과를 바탕으로 다음과 같은 제언을 하고자 한다.

농촌지역 노인의 가족건강성과 자기효능감은 유의한 관계가 있으며 노후준비 증대에 변인으로 작용함을 알 수 있다. 더욱이 자기효능감을 증진하기 위하여 화목한 가정은 물론이고, 농촌지역 노인을 위한 또래 집단과의 사회생활에서 긍정적인 상호작용이 필요하다. 궁극적으로 노인의 노후준비를 증대하기 위해서 자기효능감을 증진해야 하고, 이를 위한 경로당에서 또래와의 여가생활 여건과 경제적으로 필요한 노인 일자리 사업에 관한 지원이 필요하겠다.

첫째, 농촌지역 노인의 자기효능감을 증진하기 위하는 과정에서 경로당 교육 프로그램 개발의 필요성이 요구된다. 연구 결과 가족건강성과 자기효능감의 상호작용 효과가 유의하게 나타남을 알 수 있다. 가족건강성은 농촌지역 노인의 자기효능감에서 노후 생활의 삶의 질 향상으로 노후준비에 긍정적 경향이 나타난다. 농촌지역은 이미 초고령사회가 도래되어 도시와 비교할 때 독거노인 비율이 높고 지리적 여건이 매우 취약하여 교육프로그램 접근성이 열악한 실정이다. 아울러 농촌지역 노인에 관련된 다양한 하위 집단의 특이성을 살피고 미래 지향적 시각에서 범국가적 노인복지 정책 방안이 필요하다.

둘째, 농촌지역 노인 고용촉진 활용 방안이 요구되며, 농촌 노인의 사회 활동 프로그램 개발을 통한 노인들의 생애주기에 따른 위치 확보, 노인 스스로가 사람답게 살기 위한 제도적 노력으로 초고령사회의 제도 장치가 필요하다.

생애주기별 노인 문제는 농촌노인들을 위한 농어촌노인 복지정책 일환으로 노후준비를 위한 소득보장, 가족건강성 향상 및 자기효능감 증진을 위한 노인복지서비스의 실천 방안이 요구된다. 따라서 농촌지역 노인들의 노후준비를 증대할 수 있는 노인복지서비스 확대에 따른 복지정책과 가족건강성 향상에 영향을 미치는 자기효능감 증진에 관한 연구가 지속해서 이루어져야 할 것이며, 본 논문이 앞으로 농촌지역 노인 문제 연구에 시사점이 되길 바란다. 


\section{References}

[1] H. S. Yoon, S. R. Yeom, The Mediating Effects of Family Solidarity on Depression and Suicidal Ideation of Older Adults in Korea, Korean Journal of Social Welfare, (2016), Vol.68, No.1, pp.53-71, DOI: 10.20970/kasw.2016.68.1.003

[2] H. J. Yoo, A Study on Dual Income Married Men and Women's Family Strength Based on an Ecological Perspective, Sookmyung Women's University Graduate School, Master's thesis, pp.8-11, (2017)

[3 B. Mimi, E. M. Skaalvi, Academic Self-Concept and Self-Efficacy: How Different Are They Really?, Educational Psychology Review, (2003), Vol.15, No.1, pp.1-40, DOI: 10.1023/A:1021302408382

[4] Y. E. Oh, The Study on Variables Affecting The Rural Elderly's Loneliness and Self-Efficacy: Focused on The Mediating Effect of Social Capital, Chonnam National University Graduate School, Ph.D dissertation, pp.8-15, (2015)

[5] J. S. Seo, The Effects of Later Life Preparation on the Happiness and Life Satisfaction of the Elderly -Centered around Moderation Effects from Social Support- , Dongbang Culture University Graduate School, Ph.D dissertation, pp.18$21,(2018)$

[6] J. U. Ko, J. G. Koo, J. K. Kim, J. O. Oh, M. H. Jeong, H. S. Jeong, H. S. Cho, Elderly Welfare Theory, Yangseowon, pp.98-102, (2018)

[7] J. H. Yeom, A Longitudinal Study of Life Satisfaction Trajectory among Older Adults: Comparing Rural to Urban Areas in Korea, The Journal of Rural Society, (2016), Vol.26, No.1, pp.157-200, UCI: G704-000099.2016.26.1.004

[8] E. K. Kim, Comparison of the Factors Related to Depression of the Female Elderly Living Alone by Region, Korean Journal of Human Ecology, (2016), Vol.24, No.6, pp.811-827, UCI: G704-001335.2015.24.6.010

[9] D. M. Shin, The Effect of Perceived Self-Efficacy of Aged People on Ego Integrity: The Mediating and Moderating Effect of Spirituality, Korean Journal of Gerontological Social Welfare, (2012), No.57, pp.261-288, DOI: 10.21194/kjgsw..57.201209.261

[10] K. H. Jeong, The Effects of Family Care Giving-Burden on Middle-Aged People's Preparation for Old Age - The Mediating Effect of Self-Efficacy -, Yonsei University Graduate School, Master's thesis, pp.8-16, (2013)

[11] D. J. Park, Baby boomers' recognition of later life and the level of later life preparation, Sookmyung Women's University Graduate School, Master's thesis, pp.12-17, (2014)

[12] A. Bandura, Self-efficacy: Toward a Unifying Theory of Behavioral Change, Psychological Review, (1977), Vol.84, No.2, pp.191-215, DOI: 10.1037/0033-295X.84.2.191

[13] S. Y. Na, The Effects of College Students' Family Health on Life Satisfaction - Focusing on Mediator Effect of Achievement Motivation and Self-efficacy -, Mokpo University Graduate School, Ph.D dissertation, pp. 29-32, (2017)

[14] Y. J. Yoo, A Study on the Development of Family Program for Strengthening Family Life - Special Reference to Family Life Education -, Journal of Families and Better Life, (1991), Vol.17, No.1, pp.45-63.

[15] J. H. Kim, Y. J. Lee, Development and Evaluation of Family Strenght Promotion Program, Family and Culture, (2014), Vol.26, No.2, 189-220, DOI: 10.21478/family.26.2.201406.006

[16] G. Y. Shin, The Effects of Elderly People's Lifestyle on their Successful Later Years with a Mediating Effect of Preparation for their Later Life, Korea Academy of Care Management, (2016), No.20, pp.65-91, UCI: G704SER000003121.2016..20.006.

[17] M. W. Lee, A study about factors affecting the settlement satisfaction of retirement migration to rural areas: focusing on mediating effect of acculturation stress and self-effectiveness, Ewha Womans University Graduate School, Ph.D dissertation, pp.15-26, (2018)

[18] K. Y. Shin, J. U. Ko, Influence of the Elderly Feeling of Self-Efficacy on Preparation after Retirement -Focused on the Mediating Effect of Social Capital-, The Journal of the Korea Contents Association, (2017), Vol.17, No.9, pp.255267, DOI: 10.5392/JKCA.2017.17.09.255

[19] S. M. Lim, The Effect on life Satisfaction in Retirement Preparation and Residential Environment of the Middle-aged: Focused on the Moderating Effects of Social Capital, Hoseo University Venture Graduate School, Ph.D dissertation, 
Effects of Family Health of Elderly People in Rural Areas on Their Preparation for Old Age -Focused on the mediating effect of self-efficacy-

pp.12-50, (2016)

[20] Y. J. Yoo, I. S. Lee, S. K. Kim, H. J. Choi, Development of Korea Family Strengths Scale(KFSS-), Journal of Families and Better Life, (2013), Vol.31, No.4, pp.113-129, UCI: G704-000320.2013.31.4.003

[21] S. Y. Na, The Effects of College Students' Family Health on Life Satisfaction - Focusing on Mediator Effect of Achievement Motivation and Self-Efficacy -, Mokpo University Graduate School, Ph.D dissertation, pp.29-32, (2017)

[22] G. Y. Shin, Influence of the Elderly Feeling of Self-Efficacy on Preparation after Retirement - Focused on the Mediating Effect of Social Capital, Catholic Kwandong University Graduate School, Ph.D dissertation, pp.11-15, (2016)

[23] R. M. Baron, D. A. Kenny, The moderator-mediator variable distinction in social psychological research: Conceptual, strategic, and statistical considerations, Journal of personality and social psychology, (1986), Vol.51, No.6, pp.11731182, DOI: 10.1037/0022-3514.51.6.1173 